\title{
CLINICAL AND HEMATOLOGICAL FEATURES OF LEISHMANIASIS IN A TERTIARY CARE HOSPITAL OF PESHAWAR
}

\author{
Zufishan Batool ${ }^{1}$, Shifa Basharat ${ }^{1}$, Maria Khan², Nosheen Ali', Maria Tasneem Khattak², Gulrukh Sohail ${ }^{1}$ \\ ${ }^{1}$ Department of Pathology, Rehman Medical College, Peshawar - Pakistan \\ ²Department of Pathology, Rehman Medical Institute, Peshawar - Pakistan
}

\begin{abstract}
Objective: To evaluate the hematological and clinical features of Visceral and Cutaneous Leishmaniasis.

Materials and Methods: This was hospital-based retrospective study which included all cases of Cutaneous and Visceral leishmaniasis that were diagnosed from Jan 2018 till December 2019 at Pathology Department, Rehman Medical Institute, Peshawar. The cases were analyzed for clinical and laboratory parameters in detail, including complete blood count, demographic information and physical signs at presentation were noted along with bone marrow aspirations were analyzed for LD bodies.

Results: Out of 104 cases, 36 (34.61\%) visceral leishmaniasis and 68 (65.38\%) cutaneous leishmaniasis were observed during the study period, in which 82 (78.85\%) were male and $22(21.15 \%)$ were females. Age range was from 03-40 years with mean SD of $23 \pm 4.21$ years. Intermittent fever was observed in almost all the cases of visceral leishmaniasis and 52 $(76.47 \%)$ of cutaneous leishmaniasis. All patients with visceral leishmaniasis had hepatomegaly and splenomegaly. Patients with CL presented as lesions on face and foot region. In VL all patients were male, while in CL 46 were males and only 22 were females. Majority (83.33\%) of patients in VL were children (age group 1-10 years), in cutaneous leishmaniasis 34 (50\%) were in age group 31-40 years. Anemia and thrombocytopenia were most common hematological parameters.

Conclusion: Our study concludes that leishmaniasis mainly affecting age group 10-20 years. Patients with visceral Leishmaniasis presented with pallor, weight loss fever and splenomegaly while those with cutaneous leishmaniasis presented with lesions on the foot and face especially nose. It is essential that the Public Health authorities be more aware of the condition in order to improve environmental sanitation and personal protective measures and to establish diagnostic facilities for early and correct diagnosis and treatment.
\end{abstract}

Keywords: Leishmania donovani, cutaneous leishmaniasis, visceral leishmaniasis, bicytopenia, kalazaar.

This article may be cited as: Batool Z, Basharat S, Khan M, Ali N, Khattak MT, Sohail G. Clinical and hematological features of Leishmaniasis in a tertiary care hospital of Peshawar. J Med Sci 2020 October;28(4):348-351

\section{INTRODUCTION}

In tropical countries, Leishmaniasis is approximated to be ninth on the list of burden disease. ${ }^{1}$ There are two main types of Leishmaniasis, Visceral Leishmaniasis (VL) and cutaneous leishmaniasis (CL) caused by the Leishmania tropicana and Leishmania donovani respectively $^{2}$. Leishmania is thought to be endemic in 88 countries throughout the world. The WHO estimate of newly diagnosed cases is approximately 0.4 million globally with people at risk being approximately 400 million. The global prevalence of Leishmania is 12 million. $^{3}$

Leishmaniasis is a vector borne disease caused

\section{Correspondence}

Dr. Maria Khan

Assistant Professor,

Department of Pathology, Rehman medical institute,

Peshawar - Pakistan.

Email: kmaria22@gmail.com

Cell: +92-333-9111986

Date received: $14-05-2020$

Date revised: $\quad 29-10-2020$

Date accepted: $03-12-2020$ by female sand fly. ${ }^{4}$ Visceral Leishmaniasis (VL) usually presents with gross splenomegaly and pancytopenia and is thought to be endemic in North East region of Indian subcontinent and certain parts of Africa along with the few parts of Latin America. ${ }^{5}$ Cutaneous Leishmania (CL) is very common in north east region of subcontinent, Ghana, parts of Iran and Afghanistan. ${ }^{6-8}$ Leishmaniasis in Pakistan both cutaneous and visceral is commonly found in Azad Kashmir, Baluchistan, Multan and in Afghan refugees camps in $\mathrm{KP}^{9-13}$

Due to the increasing number of Afghan refugees in $\mathrm{KP}$, during the past few decades, a study was conducted to observe the trends in prevalence of leishmaniasis in Afghan refugees that is an emerging heath problem for the residents in the North West region of KP. The aim of our study was to assess the demographic diversity and clinicopathological manifestations of leishmaniasis and its serlogical types in North West region of Khyber Pakhtunkhwa $(\mathrm{KP})$. 
Clinical And Hematological Features Of Leishmaniasis In A Tertiary Care Hospital Of Peshawar.

\section{MATERIAL AND METHODS}

This study was an observational cross-sectional study conducted in Pathology department, Rehman medical institute, Peshawar. All cases of Cutaneous Leishmaniasis $(\mathrm{CL})$ and Visceral Leishmaniasis $(\mathrm{VL})$ presenting from January 2018 till December 2018 in histopathology/ hematology archives were included in the study. The diagnosis of VL was established by demonstrating amastigote forms of the parasites in bone marrow and in case of cutaneous by skin biopsy. All other patients presenting with bicytopenia / pancytopenia, caused by conditions other than leishmaniasis, patients with history of any other hematological disorder such as myeloproliferative diseases, myelodysplasia and CML were excluded from the study. In all cases $2.5 \mathrm{ml}$ EDTA blood was collected in commercially available vacutainer tubes and analyzed on hematology analyzer- Sysmex KX 21 with daily quality control. Peripheral blood slides were prepared and stained for smear examination. Bone marrow aspiration was performed under local anesthesia, Slides were prepared and stained with Giemsa. Marrow aspirate slides were scanned for intracellular / extracellular amastigote forms of Leishmania Donovan (LD) bodies. Clinical and laboratory profile of the diagnosed cases were analyzed in detail. All care was taken to maintain the confidentiality of the patients. This was a retrospective analysis of records and therefore, consent could not be taken. The confidentiality of the subjects was maintained while analyzing the data. The study was approved by Ethics Committee of Rehman medical Institute, Peshawar and data was analyzed using SPSS version 19.

\section{RESULTS}

Overall, 104 cases, 36 (34.61\%) visceral leishmaniasis and 68 (65.38\%) cutaneous leishmaniasis were observed during the study period, in which $82(78.85 \%)$ were male and 22(21.25\%) were females. Age range was from 03-40 years with mean of $23+4.21$ years. Age distribution is shown in table 1. Intermittent fever was observed in almost all the cases of visceral leishmaniasis and 52 (76.47\%) of cutaneous leishmaniasis. All patients with visceral leishmaniasis had hepatomegaly and splenomegaly. Patients with CL presented as lesions on cheeks, foot

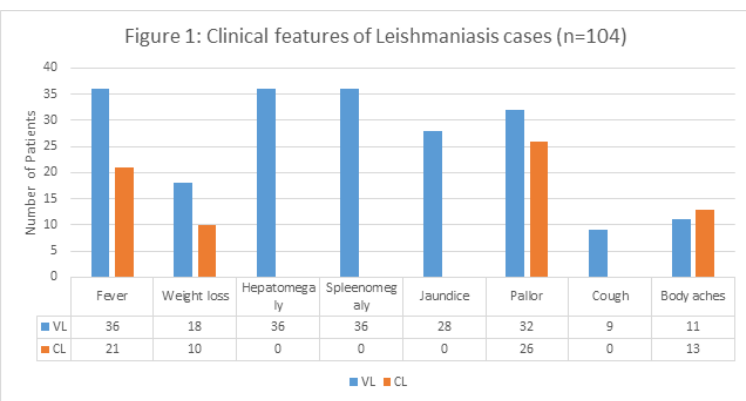

Fig 1: Clinical features of Leishmaniasis cases $(n=104)$
Table 1: Hematological parameters of patients. $(n=104)$

\begin{tabular}{|c|c|c|}
\hline Parameters & $\begin{array}{c}\text { Visceral } \\
\text { Leishmaniasis } \\
(n=36)\end{array}$ & $\begin{array}{c}\text { Cutaneous } \\
\text { Leishmaniasis } \\
(n=68)\end{array}$ \\
\hline \multicolumn{3}{|c|}{ Gender } \\
\hline Male & $36(100 \%)$ & $46(67.64 \%)$ \\
\hline Female & 00 & 22 (32.35\%) \\
\hline \multicolumn{3}{|c|}{ Age group } \\
\hline $1-10$ years & $29(83.33 \%)$ & 00 \\
\hline $11-20$ years & $04(11.11 \%)$ & $9(13 \%)$ \\
\hline 21-30 years & $03(8.3 \%)$ & $25(37 \%)$ \\
\hline $31-40$ years & 00 & $34(50 \%)$ \\
\hline \multicolumn{3}{|c|}{ Hematological parameters } \\
\hline $\begin{array}{l}\text { Hemoglobin (mean } \\
\text { SD) }\end{array}$ & $8.7 \pm 1.5$ & $9.1 \pm 2.1$ \\
\hline $\begin{array}{l}\text { Total Leucocyte count } \\
\text { (mean SD) }\end{array}$ & $5365 \pm 964$ & $5689 \pm 541$ \\
\hline Platelets (mean SD) & $75000 \pm 4210$ & $174000 \pm 7209$ \\
\hline Anemia $(\mathrm{Hb}<12 \mathrm{~g} / \mathrm{dl})$ & $36(100 \%)$ & $25(37 \%)$ \\
\hline Thrombocytopenia & $36(100 \%)$ & $42(62 \%)$ \\
\hline Leucopenia & $12(33.33 \%)$ & 00 \\
\hline Pancytopenia & $12(33.33 \%)$ & 00 \\
\hline Bicytopenia & $36(100 \%)$ & 00 \\
\hline Lymphocytosis & $6(16.66 \%)$ & 25 (38\%) \\
\hline
\end{tabular}

or nose. Clinical features are shown in figure 1. In VL all patients were male, while in CL 46 were males and only 22 were females. Majority (83.33\%) of patients in VL were children (age group 1-10 years), in cutaneous leishmaniasis majority 34 (50\%) were in age group 31-40 years. Hematological parameters are shown in Table: 1.

\section{DISCUSSION}

According to the World Health Organization (WHO), leishmaniasis affects around two million people annually, 500,000 cases of which are of the visceral form. It is estimated that $\mathbf{3 5 0}$ million people are exposed to the risk of infection, with a global prevalence of 12 million infected individuals. ${ }^{14}$

This study was conducted to find out the clinical and hematological changes associated with visceral and cutaneous leishmaniasis in tertiary care hospital of Peshawar. Majority $78.85 \%$ of patients in our study were males. Predominance of males in our study could be due to gender bias in the male dominant society or it may be due to greater exposure of our males than females. In our cases, fever, hepatomegaly and splenomegaly was also seen in all the cases of VL (100\%), jaundice in 5 (83.33\%) cases. Weight loss in 18 (50\%) VL, 10 (14.7\%) (CL) and pallor in 32 (88.9\%) VL, 26 (38.2\%) CL cases. In a study by Rai et al,15 majority of the patients (98\%) presented with fe- 
ver followed by Pallor (44\%), weight loss (43\%), diarrhea $(17 \%)$, vomiting (15\%) and hepatosplenomegaly (83\%). In the same study lymphadenopathy (20\%), purpura (13\%) and peripheral edema (11\%) was reported, which was not seen in our cases. Dhingra et al ${ }^{16}$ reported fever in $70 \%$ of cases and splenomegaly in $100 \%$ of cases with VL. Another study showed pyrexia in $100 \%$ of cases in VL, which was same as our findings. ${ }^{17}$

Anemia and thrombocytopenia were the most common hematological disorders in this study as evident in other studies. ${ }^{18,19}$ On peripheral blood smear, RBC showed microcytic hypochromic blood picture in majority of cases similar to studies conducted by Hamid et al.20 Pancytopenia was also a common hematological abnormality similar to other study done by Splenic sequestration of the blood cell is the major cause of Pancytopenia in Kala-azar. ${ }^{6}$ Suppression of the bone marrow due to high burden of the infection is relatively rare. Bicytopenia were also observed in VL cases, whereas it was reported in $77 \%$ of patients and pancytopenia in $23 \%$ of cases in a local study. ${ }^{21}$ This is consistent with our study, as $33.33 \%$ of the patients had pancytopenia, $100 \%$ of VL had bicytopenia, and none of $C L$ cases had bicytopenia or pancytopenia. Most of the patients of cutaneous leishmaniasis had single lesion on the foot $(50 \%)$, cheek $(28 \%)$ and $22 \%$ were on the nasal tip. This is similar to a study carried out in KP during 2016 , where more than $40 \%$ of the lesions were found on the lower extremity. ${ }^{22}$ Limitation of our study was that it was a single centered study and should be duplicated in other centers for further research on Leishmaniasis.

\section{CONCLUSION}

Patients with visceral Leishmaniasis presented with pallor, weight loss fever and splenomegaly while those with cutaneous leishmaniasis presented with lesions on the foot, cheek and nasal tip. The common age group of presentation was 10-20 years, with anemia and thrombocytopenia as the most common hematological parameters. It is essential that the Public Health authorities be more aware of the condition in order to improve environmental sanitation and personal protective measures and to establish diagnostic laboratories for early and correct diagnosis and treatment

\section{REFERENCES}

1. Hotez PJ, Molyneux DH, Fenwick A, Ottesen E, Sachs SE, Sachs JD. Incorporating a rapid-impact package for neglected tropical diseases with programs for HIV/AIDS, tuberculosis, and malaria. PLoS Med. 2006; 3(5):576-84.

2. Desjeux P. Leishmaniasis: current situation and new per- spectives. Comp Immunol Microbiol Infect Dis. 2004; 27(5):305-18.

3. Ullah S, Jan AH, Wazir SM, Ali N. Prevalence of cutaneous leishmaniasis in lower Dir District (NWFP), Pakistan. J Pak Assoc Dermatol. 2009; 19(1):212-5.

4. Huda MM, Kumar V, Das ML, Ghosh D, Priyanka J, Das $P$ et al. Entomological efficacy of durable wall lining with reduced wall surface coverage for strengthening visceral leishmaniasis vector control in Bangladesh, India and Nepal. BMC Infect Dis. 2016; 16(1):539

5. Ready PD. Epidemiology of visceral leishmaniasis. Clin Epidemiol. 2014; 6:147.

6. Mollalo A, Alimohammadi A, Shirzadi MR, Malek MR. Geographic information system-based analysis of the spatial and spatio-temporal distribution of zoonotic cutaneous leishmaniasis in Golestan Province, north-east of Iran. Zoonoses Public Health. 2015; 62(1):18-28.

7. Kwakye-Nuako G, Mosore MT, Duplessis C, Bates MD, Puplampu N, Mensah-Attipoe I et al. First isolation of a new species of Leishmania responsible for human cutaneous leishmaniasis in Ghana and classification in the Leishmania enriettii complex. Int J Parasitol. 2015; 45(11):679-84.

8. Kakarsulemankhel JK. Leishmaniasis in Pak-Afghan Region. Int J Agric Biol. 2011; 13(4):611-20.

9. Altaf C, Ahmed P, Ashraf T, Anwar M, Ahmed I. Clinicopathological features of childhood visceral leishmaniasis in Azad Jammu \& Kashmir Pakistan. J Ayub Med Coll Abbottabad. 2005; 17(4):48-50

10. Bhutto AM, Soomro RA, Nonaka S, Hashiguchi Y. Detection of new endemic areas of cutaneous leishmaniasis in Pakistan: a 6-year study. Int J Dermatol. 2003; 42(7): 543-8

11. Yasinzai MM; Chang KP. Leishmaniasis in Pakistan: development of potent chemotherapeutic agent. J Parasitic Dis .1996; 20(1): 70- 8.

12. Rahim F, Jamal S, Raziq F, Uzair M, Sarwar B, Ali H, et al. An outbreak of Cutaneous Leishmaniasis in a village of district Dir. JPMI. 2003; 17(1): 9.

13. Ayub S, Gramiccia M, Khalid M, Mujtaba G, Bhutta RA. Cutaneous Leishmaniasis in Multan: species identification. J Pak Med Assoc. 2003; 53(10): 445-7.

14. Dhingra KK, Gupta P, Saroha V, Setia N, Khurrana N, Singh T. Morphological findings in bone marrow biopsy and aspirate smears of visceral Kala azar: A review. Indian J Pathol Microbiol. 2010;53(1):96-100

15. World Health Organization. Global health situation in selected infections and parasitic diseases due to identification organisms. Wkly Epidemiol Rec 1993; 641-8.

16. Rai ME, Muhammad Z, Sarwar J, Qureshi AM, Hematological findings in relation to clinical findings of visceral Leishmaniasis in Hazara Division. J. Ayyub Med Coll Abbottabad. 2008; 20 (3): 40-43. 
17. Dhingra KK, Gupta P, Saroha V, Setia N, Khurrana N, Singh T. Morphological findings in bone marrow biopsy and aspirate smears of visceral Kala azar: A review. Indian J Pathol Microbiol. 2010;53(1):96-100

18. Agarwal Y, Sinha AK, Upadhyaya P, Kafle SU, Rijal S, Khanal B. Haematological Profile in visceral leishmaniasis. Int J Infect Microbiol. 2013; 2(2):39-44.

19. Agarwal $Y$, Sinha AK, Upadhyaya P, Kafle SU, Rijal S, Khanal B. Haematological Profile in visceral leishmaniasis. Int J Infect Microbiol. 2013; 2(2):39-44.

20. Shoaib A, Wajiha R, Ali I, Zafar Z, Sumaira Z, Khalid F, Awan MU. Visceral leishmaniasis- A study of 42 cases. Ann Pak Inst Med Sci. 2009; 5(3):151-3.

21. Hamid GA, Gobah GA. Clinical and haematological manifestations of visceralleishmaniasis in Yemeni children. Turk J Haematol. 2009; 26(1):25-8.

22. Shah sm, khattak az, ghori mr, batool z. Clinical and hematological presentation of visceral leishmaniasis in children in a tertiary care hospital. J Med Sci. 2012;20(2):947

23. Khan NH, ul Bari A, Hashim R, Khan I, Muneer A, Shah A et al. Cutaneous leishmaniasis in Khyber Pakhtunkhwa province of Pakistan: clinical diversity and species-level diagnosis. Am J Trop Med Hyg. 2016; 95(5):1106-14.
CONFLICT OF INTEREST: Authors declare no conflict of interest

GRANT SUPPORT AND FINANCIAL DISCLOSURE: NIL

\section{AUTHOR'S CONTRIBUTION}

Following authors have made substantial contributions to the manuscript as under

Batool Z: $\quad$ Conceptualized and designed the study

Basharat S: Methodology, data collection

Khan M: $\quad$ Methodology, data collection, writting of manuscript

Ali N: $\quad$ Statistical analysis, review of manuscript

Khattak MT: Data collection

Sohail G: Data collection, Biblography

Authors agree to be accountable for all aspects of the work in ensuring that questions related to the accuracy or integrity of any part of the work are appropriately investigated and resolved. 